\title{
PCR Inhibitory Effects of Aldehyde Fixing Agents on DNA Extracted from Embalmed Human Skeletal Fragments and Teeth Specimens
}

\author{
Ad Zagga, ${ }^{1}$ Aa Tadros, ${ }^{1}$ Sm Ismail, ${ }^{2}$ And H Ahmed, Oon. ${ }^{3}$ \\ ${ }^{I}$ Department of Anatomy, College of Health Sciences, Usmanu Danfodiyo University, Sokoto, Sokoto State, \\ Nigeria. \\ ${ }^{2}$ Department of Medical Molecular Genetics, Division of Human Genetics and Genome Research, National \\ Research Centre, Cairo, Egypt. \\ ${ }^{3}$ Department of Paediatrics, College of Health Sciences, Usmanu Danfodiyo University, Sokoto, Sokoto
} State, Nigeria.

\begin{abstract}
The presence of inhibitors in samples has been the focus of much of the published literature. The difficulties posed by PCR inhibitor-bearing DNA samples have traditionally been addressed by decreasing the inhibitor concentration, either through sample dilution or by further purifying the target DNA. A review composed via Medline Internet search, literature search and contributions from our experiences as well as experiences from colleagues. The recovery of intact high-molecular-weight DNA from formaldehyde-fixed tissues is very poor and that this fragmented DNA amplifies poorly in PCR reactions. For the fact that aldehyde fixed samples of bone or tooth may contain many different inhibitory substances leading to failure of amplification, a multi-faceted approach is the best solution for amplification failure.
\end{abstract}

Key words: PCR, inhibition, aldehydes, bone, teeth

\section{Introduction}

PCR inhibitors are a very heterogeneous group of chemical substances. One certain matrix may contain many different inhibitory substances and the same inhibitors can be found in many different matrices. Organic as well as inorganic substances, which may be dissolved or solid, can appear as PCR inhibitors. Calcium ions are an example for inorganic substances with inhibitory effects on the PCR. However, most of the known inhibitors are organic compounds, for example, bile salts, urea, phenol, ethanol, polysaccharides, sodium dodecyl sulphate (SDS), humic acids, tannic acid, melanin as well as different proteins, such as collagen, myoglobin, haemoglobin, lactoferrin, immunoglobin $\mathrm{G}(\mathrm{IgG})$ and proteinases [1]. Besides the substance class, the concentration of the compound is important for its inhibitory effect. PCR inhibitors can be found in a variety of biological materials (organs like bones and teeth, blood, body fluids etc.), environmental samples (water, soil, air etc.) and food (meat, milk, fruits, vegetables, seafood etc.). In addition, inhibitory substances may also be unintentionally added during transport, sample processing (e.g. pre-concentration procedures) or nucleic acid extraction [2].

For as long as scientists have used the polymerase chain reaction (PCR), PCR inhibitors have been an obstacle to success. All who use PCR are likely to be impacted by inhibitors at some time, but the wide range of forensic sample types and variety of sampling conditions encountered make forensic scientists particularly vulnerable. PCR inhibitors generally exert their effects through direct interaction with DNA or interference with thermostable DNA polymerases. Direct binding of agents to singlestranded or double-stranded DNA can prevent amplification and facilitate co-purification of inhibitor and DNA. Inhibitors can also interact directly with a DNA polymerase to block enzyme activity. DNA polymerases have cofactor requirements that can be the target of inhibition. Magnesium is a critical cofactor, and agents that reduce $\mathrm{Mg} 2+$ availability or interfere with binding of $\mathrm{Mg} 2+$ to the DNA polymerase can inhibit PCR [3].

When an organism dies, its DNA normally becomes degraded by endogenous nucleases. Under certain circumstances, such as rapid desiccation, low temperatures or high salt concentrations, nucleases can themselves become destroyed or inactivated before all nucleic acids are reduced to mononucleotides. If this is the case, slower but still relentless processes start affecting the DNA. For example, oxidation, as well as the direct and indirect effects of background radiation, will modify the nitrous bases and the sugar-phosphate backbone of the DNA [4]. Furthermore, deamination, depurination and other hydrolytic processes will lead to destabilization and breaks in DNA molecules. All these processes create problems for the retrieval of DNA sequences. For example, a high proportion of cytosine and thymine residues in extracts of ancient tissues are oxidatively modified to hydantoins oxidation products of the pyrimidine bases (cytosine and thymine), which block DNA 
polymerases and thus the PCR. Furthermore, deamination products of cytosine, for example, are common in DNA and cause incorrect bases to be inserted during the PCR [4].

In cadavers, DNA degrades very quickly, even in early post-mortem periods. The degradation of soft tissues is particularly evident after short intervals of time, a consequence of the rapid bacterial increase that is natural in decomposing corpses, especially in those that are exposed to hot temperatures in tropical countries [5].

Another common problem is the presence of inhibitors of DNA analysis that could be present [6]. The majority of extracted PCR inhibitors are tannins, humic acids and fulvic acids, all common soil-derived degradation products. Because they are highly phenolic, they generally should be removed by phenolchloroform extraction. Another class of inhibitors are maillard products, by-products of sugar reduction, which cross-link macromolecules, including nucleic acids. Humic acids, fulvic acids and maillard products often result in brown cloring of DNA extracts. These compounds often fluoresce blue in agarose gel under ultraviolet (UV) light [4].

Secondly, high molecular weight DNA, that is, that which can be analyzed, in human remains or in recent post-mortem material, is very scarce due to the degradation of genetic material. Exogenous agents, like microorganisms, humidity and many organic compounds, to which the corpses were exposed, also reduce the amount of informative DNA available [7].

\subsection{Aldehyde Fixing Agents and Their Mechanism of PCR Inhibition}

In the fields of Anatomy, histology, pathology and cell biology, fixation is a chemical process by which biological tissues are preserved from decay, thereby preventing autolysis or putrefaction. Fixation terminates any ongoing biochemical reactions, and may also increase the mechanical strength or stability of the treated tissues. Fixation of tissue is done for several reasons. One reason is to kill the tissue so that postmortem decay (autolysis and putrefaction) is prevented. Fixation preserves a sample of biological material (tissue or cells) as close to its natural state as possible in the process of preparing tissue for examination [8].

Aldehyde fixing agents, such as formaldehyde and paraformaldehyde, are potent cross-linking agents. The majority of products are protein-protein cross-links with less cross-linking of protein to DNA and virtually no cross-linking of DNA to DNA at room temperature [9]. Formaldehyde fixation has a number of drawbacks which are familiar to histologists but which are not often appreciated by most PCR investigators. First, it is difficult to remove totally from tissues, even with extensive washing for several days [10]. The residual formaldehyde groups left in tissue can continue forming cross-links with protein or nucleic acids long after the agent has been removed [11]. It is therefore quite possible that formaldehyde-fixed tissue can also react with PCR reagents after they have been added [9].

A second and probably more important property of formaldehyde is its ability to cross-link the histones which normally coat DNA. This property was originally used to elucidate the structure of nucleosomes. Proteinprotein cross-linking occurs mainly within the histone octamer, but can occur between nucleosomes on the same DNA molecule [12]. The extent of DNA-protein cross-links is governed by the degree of association between DNA and the protein molecule. Cross-linked histones are likely to be a major obstacle to the progression of Taq polymerase along the target DNA and they also impose constraints on the size of the PCR products that can be generated. Teo and Shaunak (1995) [9] demonstrated that cross-linking of histones on plasmid DNA by formaldehyde severely reduces its ability to be amplified by PCR.

The problems associated with cross-linking of histones on DNA by formaldehyde have been recognized by investigators performing solution-based PCR on archive material and they have consequently used extensive protease digestion (e.g. up to 5 days at $37^{\circ} \mathrm{C}$ [13]. Extensive protease digestion of cells cannot be performed prior to PCR because it would destroy the architecture of the cell and contribute to diffusion of PCR products out of the cell [14]. The relatively mild protease steps often used are unlikely to completely unmask the DNA and there is even some evidence to suggest that residual part of the core of formaldehyde-fixed histone remains resistant to protease digestion [15].

Other types of non-cross-linking damage to DNA are also likely. Formaldehyde treatment causes single-strand breaks in treated cells [16], though to what extent these are the result of excision repair processes is unclear [9]. It is worth noting that the recovery of intact high-molecular-weight DNA from formaldehydefixed tissues is very poor [17], and that this fragmented DNA amplifies poorly in PCR reactions. Teo and Shaunak (1995) [9] suggest that part of the failure to amplify DNA from fixed cells may be due to the presence of large numbers of single-stranded breaks in the target DNA.

Formaldehyde treatment of a polynucleotide substrate causes misincorporation of nucleotides into DNA by DNA polymerase in an in vitro system [18] and it is likely that this is the basis for the mutagenic effects of formaldehyde in vivo. It is not known, however, what effect such DNA modifications have on the fidelity and processivity of Taq polymerase [9] 
Non-aldehyde fixatives do not form cross-links between proteins and nucleic acids, but fix tissues through precipitation. In the context of PCR in situ they should allow more efficient amplification from the target DNA because histones are not removed by digestion with protease. Their use in tissue subjected to PCR has, however, been limited [9]. Nuovo et al. (1993) [14] have performed PCR on cells fixed with actone, ethanol and methanol-acetic acid and poor retention of short (115 bp) PCR amplified products generated using a single primer pair. These findings were attributed to the inability of these agents to perform the cross-linked lattice structures necessary to trap PCR amplified products within cells. Conversely, Chiu et al. (1992) [19] and Patterson et al. (1993) [20] have successfully used the non-cross-linking agents methanol-acetic acid and STF (Streck fixative) respectively. In both cases, the investigators used multiple primer pairs to generate long amplification products which should have been better retained in the absence of a cross-linked 'lattice' structure.

DNA extracted from formaldehyde-fixed tissue and analysed on gels has an average size of 200 to $2000 \mathrm{bp}$ (compared to $>30 \mathrm{~kb}$ for unfixed tissue). This accounts for the difficulties in amplifying sequences $>$ 400 bp in solution-based PCR [21]. Even allowing for DNA strand breakage during extraction, there are still an excessive number of breaks in formaldehyde-fixed material. Both single- and double-stranded DNA breaks can occur [21].

Teo and Shaunak (1995) [9] found that when using some of the published PCR protocols, there is poor denaturation of DNA in formaldehyde-fixed cells during the early circles of PCR. This observation is somewhat surprising because formaldehyde is a denaturing agent often used in RNA and DNA agarose gel electrophoresis.

Cross-linking of histones to each other and to the target DNA is likely to act both as a block to denaturation over long stretches and to accelerate renaturation [9]. Using in vitro model system, Cox and Lehman (1981) [22] have demonstrated that the renaturation of DNA is promoted by histones with a $\mathrm{t}_{1 / 2}<1 \mathrm{~min}$. The reaction is also cateion-dependant. Bagarasa et al. (1992) [23] performed a heating step on cells before fixation with paraformaldehyde. Under these conditions, it is likely that denaturation of the target DNA is achieved prior to fixation, thereby 'freezing' the DNA in a state whereby cross-linked histones (if still attached) interfere less with PCR amplification [9].

\subsection{PCR Inhibition of Aldehydes on DNA Extracted from Human Skeletal Fragments and Teeth Specimens}

Since the paper by Hochmeister et al., 1991 [24], reporting on the successful amplification of DNA extracted from human femoral bone of a corpse submerged 18 months under water and a 11 -year-old mummified-corpse, other studies in the literature report have demonstrated the ability to amplify DNA from ancient and formalin fixed sketel fragments and teeth specimens.

Faerman et al. (1995) [25], determined sex in skeletal remains of 18 individuals, including young children, out of 22 examined from periods ranging from 200 to around 8000 years ago based on amplification of single-copy amelogenin-encoding gene $(A M G)$.

Stone et al., (1996) [26], amplified a small fragment (112 bp) in exon 6 of the amelogenin gene to accurately determine genetic sex of 19 out of 20 ancient human skeletons dating to A. D. 1300.

Faerman et al. (1998) [27], determined the sex of infanticide victims from the late Roman era through ancient DNA analysis. Amplification was successful for 19 only out of the 43 ancient specimen tested.

Mays and Faerman (2001) [28], reported on sex identification in some putative infanticide victims from Roman Britain using ancient DNA. Sex identification was performed using a method based on PCR amplification of the $\mathrm{X}$ and $\mathrm{Y}$ amelogenin alleles. Only the $\mathrm{Y}$ amelogenin allele could be amplified in all nine male samples, thus reflecting a relative poor state of DNA preservation in the bone specimen.

Matheson and Loy (2001) [29] used amelogenin gene in the genetic sex identification of 9400-year-old ten human skull samples from Çayönü Tepesi, Turkey. The amelogenin amplifications did not amplify efficiently and reliably, this could be due to degree of fragmentation of the DNA in these same samples.

Diane et al. (2003) [30], co amplified amelogenin, two X-chromosomal short tandem repeats (STRs) (DXS6789 and DXS9898) and two Y-chromosome specific STRs (DYS391 and DYS392). The amplification results of this multiplex approach back each other up, and enable reliable sex identification.

Vaňharová and Drozdová (2008) [31], reported concordance between the genetic and archeological determinations occurred in 13 cases out of $21(\sim 62 \%)$ on the sex determination of 53 skeletal remains of 4000 year old children and juveniles using amelogenin.

Shahrul Hisham and his colleagues, reported in 2009 [32], on the successful molecular gender determination of 2 ancient human bones, using amelogenin gene.

Zagga 2011 [33] reported a success rate of $43 \%$ and $0 \%$ respectively, for gender identification of embalmed bone samples and embalmed cadaveric teeth specimens with amelogenin gene.

Lin et al. (1995) [34] reported that with alphoid repeat primers sex determination was possible even with very ancient human bone samples $>1300$ years. 
Cipollaro et al., (1999) [35] reported on the successful amplification of ancient (79 A.D) DNA and gender determination of 8 femuri, 4 tibia and 1 humerus from Pompeii Archaeological Site, using Y-specific alphoid repeats. However, there was no amplification in 1 tibia due to very poor preservation of the specimen. The

Murakami et al., (2000) [36], determined genetic sex of pulp in all 20 teeth (10 males 10 females) preserved at room temperature for 22 years using alphoid repeats. The sex of a mummified body estimated to have been discovered half a year to 1 year after death could be determined readily by examination of the dental pulp. In the skeletons of 2 bodies placed under water for approximately 1 year and approximately 11 years 7 months, pulp tissues had been dissolved and lost, but sex determination was possible using DNA extracted from hard dental tissue.

Matheson and Loy (2001) [29] reported a success rate of 90\% amplification and subsequent genetic sex identification of 9400-year-old ten human skull samples usin alphoid repeats primers.

Zagga, 2011[33] was able to amplify and determine genetic sex in about $57 \%$ of human embalmed bone samples using alphoid repeat primers. Although PCR gender determination of embalmed teeth (from cadavers), using alphoid repeats primers recorded $100 \%$ success, amplification of $Y$ chromosome was achieved in 2 out of 3 samples.

The DNA of fixed tissues or cells for PCR contains naturally occurring strands breaks which have been estimated at 3000-4000 single-strand breaks per genome in quiescent lymphocytes for example [37]. DNA strand breaks can also arise from cellular senescence, DNA repair processes, apoptotic events, nuclease activity during formaldehyde fixation or post-fixation treatments such as peroxide and thermal cycling [38].

\section{Conclusion}

For the fact that aldehyde fixed samples of bone or tooth may contain many different inhibitory substances leading to failure of amplification, a multi-faceted approach is the best solution for amplification failure.

\section{References}

[1] P. Rådström, R. Knutsson, P. Wolffs, M. Lovenklev, C. Löfström, Pre-PCR processing: strategies to generate PCR-compatible samples, Mol Biotechnol, 26, 2004, 133-146.

[2] C. Schrader, A. Schielke, L. Ellerbroek, R. Johne, PCR inhibitors - occurrence, properties and removal, Journal of Applied Microbiology, 113 (5), 2012, 1014-1026.

[3] J. Bessetti, PCR Inhibition: Profiles in DNA Promega Corporation. Assessed from www.promega.com on Saturday $20^{\text {th }}$ July, 2013

[4] Y.H. Hisham, and E.I. Muntaser, The ancient DNA. Institute of Endemic Diseases and Sudan National Museum, Sudan, 2003.

[5] E.S.M. Iwamura, J.A. Soares-Vieira, D.R. Munoz, Human identification and analysis of DNA in bones, Rev Hosp Clin Fac Med Sao Paulo. 59, 2004, 383-8

[6] J. Burger, S. Hummel, B. Herrmann, and W. Henke, DNA preservation: a microsatellite-DNA study on ancient skeletal remains, Electrophoresis, 20, 1999, 1722-8

[7] C.M. Ruitberg, D.J. Reeder, and J.M. Betler, STR Base: a short tandem repeat DNA database for the human identity testing community, Nucl Ac Res, 29 (1), 2000, 320-2.

[8] L. Carson Freida, Christa Hladik, Histotechnology: A Self-Instructional Text (3 ed.). Hong Kong: American Society for Clinical Pathology, 2009.

[9] I.A. Teo, and S. Shaunak, Polymerase chain reaction in situ: an appraisal of an emerging technique. Histochemical Journal, 27, 1995, 647-659.

[10] H. Puchtler, and S.N. Meloan, On the chemistry of formaldehyde fixation and its effects in immunohistochemical reactions, Histochemistry. 82, 1985, 201-4.

[11] A.G.E. Pearse, Histochemistry: Theoritical and Applied, Vol. 1. $4^{\text {th }}$ edn, Edinburgh: Churchill Livingstone, 1980.

[12] V.Jackson, Deposition of newly synthesized histones hybrid nucleosomes are not tandem ly arranged on daughter strands, Biochemistry, 27, 1988, 2109-20.

[13] K.F. Forsthoefal, A.C. Papp, P.J. Snyder, and T.W. Prio, Optimization of DNA extraction from formalin fixed tissue and its clinical application in Duchenne muscular dystrophy, AM. J. Clin. Pathol, 98, 1992, 98-104.

[14] G.J. Nuovo, F. Gallery, P. Macconnel, and W. Bloch, Importance of different variables for enhancing in situ detection of PCRamplified DNA, PCR Meth. Appl, 2, 1993, 305-12.

[15] D. Doenecke, Digestion of chromasomal proteins in formaldehyde treated chromatin, Hoppe Scylas/Physiol Chem, 359, 1978, 1343052 .

[16] R.C. Grafstrom, A.J.R. Fornace, and C.C. Harris, Repair of DNA damage caused by formaldehyde in human cells, Cancer Res, 44, $1984,4323-7$

[17] P. T. Moerkerk, H.J. Kesselas, J. Ten-Kate, A.F.P.M. De-Goeij, and F.T. Bosman, Southern and dot blot analysis of from formalinfixed, paraffin-embedded tissue samples from colonic carcinomas, Virchous Arch. B Cell Pathol, 58, 1990, $351-5$.

[18] R.D. Snyder, and B. Van Houten, Genotoxicity of formaldehyde and an evaluation of its effects on the DNA repair process in human diploid fibroblasts, Mutat. Res, 165, 1986, 21-30.

[19] K.P. Chiu, S.H. Cohen, S.H. Morris, $x$ and G.W. Jordan, Intracellular amplification of proviral DNA in tissue sections using the polymerase chain reaction, J. Histochem. Cytochem, 40, 1992, 333-41.

[20] B.K. Patterson, M. Till, P. Otto, C. Goolsby, M.R. Furtado, L.J. Mcbride, and S.M. Wolinsky, Detection of HIV-1 DNA and messenger RNA in individual cells by PCR-driven in situ hybridization and flow cytometry, Science, 260, 1993, 976-9.

[21] D. Crisan, and J.C. Mattson, Retrospective DNA analysis using fixed tissue specimen DNA Cell Biol, 12, 1993, $455-64$.

[22] M.M. Cox, and I. R. Lehman, Renaturation of DNA: a novel reaction of histones, Nucleic acids Res, 9, 1981, 389-400. 
[23] O. Bagarasa, S.P. Hauftman, H.W. Lischner, M. Sachs, and R.J. Pomerantz, The etection by in situ polymerase chain reaction of provirus in mononuclear cells of certain individuals infected with HIV-1, Eng. J. Med, 326, 1992, 1385-91.

[24] M.N. Hochmeister, B. Budowle, U. V. Borer, O. Rudin, M. Bohnert, R. Dirnhofer, Confirmation of the human skeletal remains using multiplex PCR amplification and typink kits, J Forensic Sci, 40, 1994, 701-5.

[25] M. Faerman, D. Filon, G. Kahila, C.L. Greenblatt, P. Smith, A. Oppenheim, Sex identification of archaeological human remains based on amplification of the X and Y amelogenin alleles, Gene, 167, 1995, 327-332.

[26] A.C. Stone, G.R. Milner, S. Paabo, M. Stoneking, Sex Determination of ancient human skeletons using DNA, American Journal of Physical Anthropology, 99, 1996, 231- 238.

[27] M. Faerman, K.G. Bar-Gal, D. Filon, C.L. Greenblatt, L. Stager, A. Oppenheim, P. Smith, Determining the Sex of Infanticide Victims from the Late Roman Era through Ancient DNA Analysis, Journal of Archaelogical Science, 25, 1998, 861-865.

[28] S. Mays, M. Faerman, Sex Identification in Some Putative Infanticide Victims from Roman Britain Using Ancient DNA, Journal of Archaeological Science, 28, 2001, 555-559.

[29] D.E. Matheson T.H. Loy, Genetic Sex Identification of 9400-old Human skull Samples from Cayönü Tepesi, Turkey, Journal of Archaeological Science, 28, 2001, 569-575.

[30] S. Diane, H. Susanne, H. Bernd Brief communication: Multiplex X/Y-PCR improves sex identification in aDNA analysis, American Journal of Physical Anthropology, 121(4), 2003, 337-341.

[31] M. Vanharova, E. Drozdova, Sex determination of skeletal remains of 4000 year old children and juveniles from Hostice 1 za Hanou (Czech Republic) by ancient DNA analysis, Anthropological Review, 71, 2008, 63-70.

[32] Z.A. Shahrul Hisham, S. Sahidan, M.A.W. Rohaya, M.Y. Siti Ateefah, Z.A. Intan Zarina, J.A.N. Nor Hidayah, R.M.A. Nadiah, Z.A. Zaidah, Molecular gender determination of ancient human from Malay Peninsular. American Journal of Applied Sciences, 6 (10), 2009, 1770-1775.

[33] A.D. Zagga, Polymerase Chain Reaction (PCR)-Based Sex Determination Using Human Skeletal Fragments and Teeth Specimens, From Sokoto, Northwestern Nigeria. A Thesis Submitted to the Postgraduate School, Usmanu Danfodiyo University, Sokoto, Nigeria, in Fulfillment for the Degree of Doctor of Philosophy in Anatomy, 2011.

[34] Z. Lin", T. Kondo", T. Minamino" M. Ohtsuji” M. Nishigami" T. Takayasu" R. Sunb T. Ohshima”, Sex determination by polymerase chain reaction on mummies discovered at Taklamakan desert in 1912, Forensic Science International, 75, 1995, 197-205.

[35] M. Cipollaro, G. Di Bernardo, A. Forte, G. Galano, L. De Masi, U. Galderisi, F.M. Guarino1, F. Angelini1, A. Cascino. Histological Analysis and Ancient DNA Amplification of Human Bone Remains Found in Caius Iulius Polybius House in Pompeii, Croatian Medical Journal, 40 (3), 1999, 1-6.

[36] H. Murakami, Y. Yamamoto, K. Yoshitome, T. Ono, O. Okamoto, Y. Shigeta, et al, Forensic study of sex determination using PCR on teeth samples, Acta Med Okayama, 54, 2000, 21-32.

[37] I.G. Kaplan, D.L. Brown, N. Chaly, W.L. Greer, K.V. Prasad, A. Severeni, and B.M. Sahai, Structural and evolutionary implications of the packaging of DNA for differentiation and proliferation in the lymphocyte, J. Mol. Evol, 26, 1987, 173-9.

[38] C.E. Gustafson, R.A. Alm, and T.J. Trust, Effect of heat denaturation of target DNA on the PCR amplification, Gene, 123, 1993, $241-4$. 